\title{
OBSERVATIONS OF THE WOODCHUCK IN WEST-CENTRAL SASKATCHEWAN, 1932-1937
}

\author{
By the late R. D. SYMONS
}

Previous to 1932 I had not personally observed or heard of a Woodchuck or Ground Hog Marmota monax, in the farming country about the Battlefords. I had, however, observed them as occurring somewhat sparingly in the evergreen belt as far south as Brightsand Lake and Midnight Lake, and in the Thickwood Hills near Hafford. Farther east, towards Prince Albert, they were quite common.

Since 1930 I have heard of several observations farther south and west than expected. My own records date from 1932; these casual occurrences probably indicate an extension of their range.
It is possible that this gradual range extension has been going on over a number of years since several oldtimers in the north say that there are more Woodchucks now (in the 1930's) than there were in earlier, decades.

It is not uncommon to find that after naturalists have pretty well established the range of a certain species it unexpectedly crops up in an area outside of this range. This is often followed by others being seen in the same district, thus upsetting previous calculations. This indicates a great deal of elasticity in the choice of abode. We have yet to. learn whether in such cases a species is extending its range, or only re-

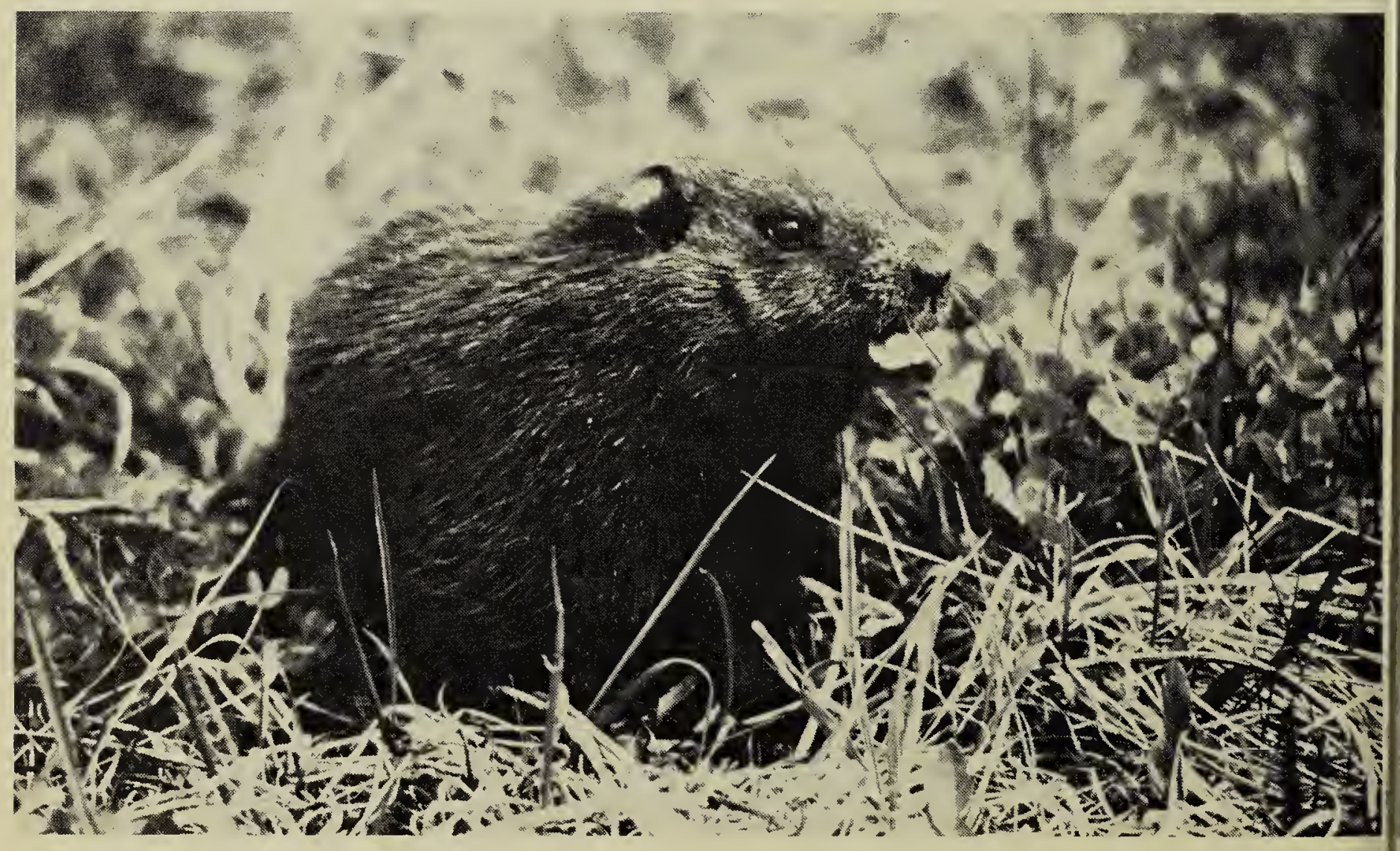


occupying areas previously abandoned for some unknown reason. Cases in point for district birds are as follows:

1935: Large numbers of Lark Buntings were seen throughout the Battleford area, where such birds were totally un- known before. One pair nested at Meota, well into the parkland country.

1934: Sprague's Pipit and Bartramian Sandpiper (Upland Sandpiper) noted as breeding in open space in northern coniferous forest north of Midnight Lake.
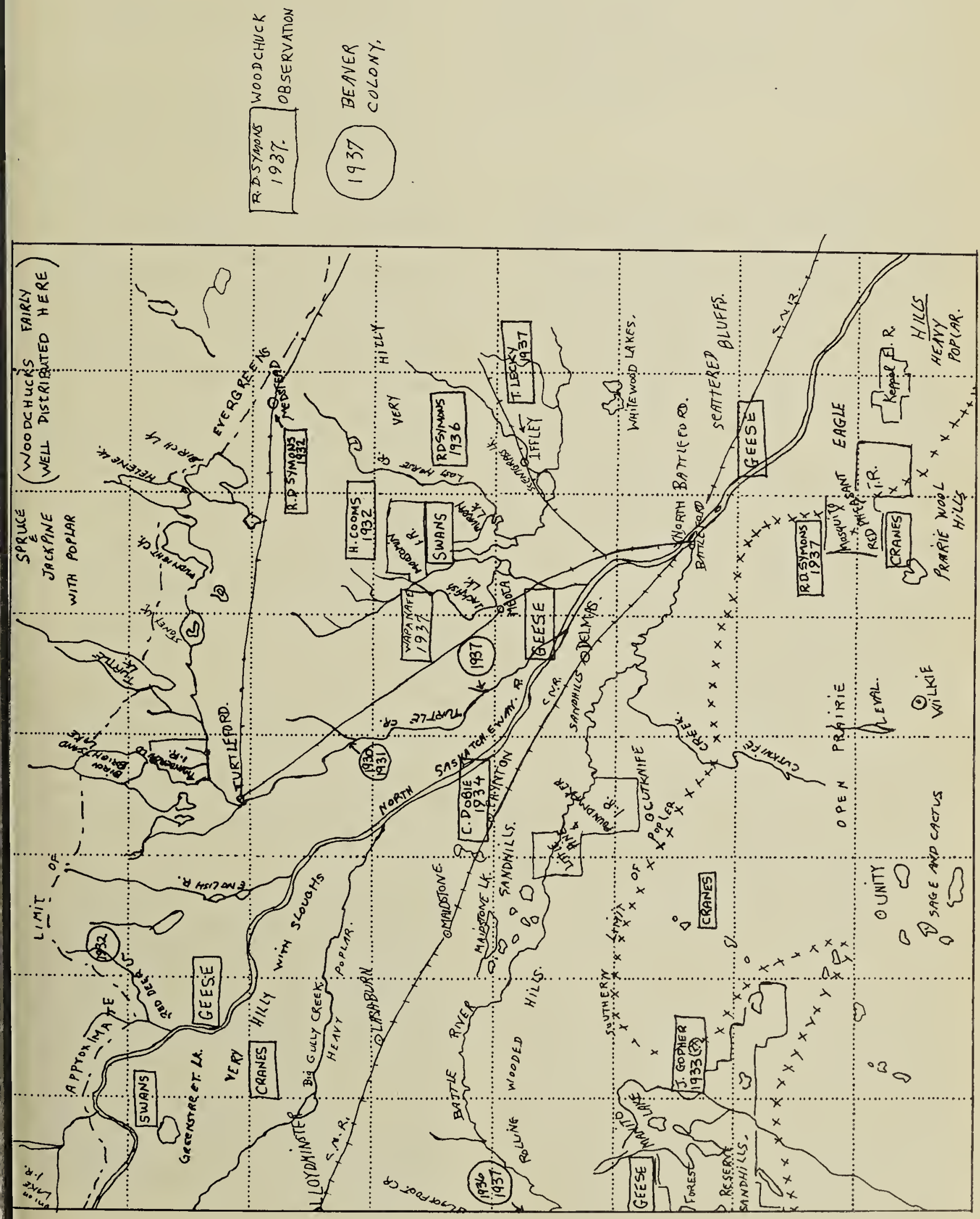

lap of area abridged from Symon's report. 
1930 and 1936: Burrowing Owl noted as nesting near Cutknife. Whip-poorwill observed several evenings in succession at Nelson's farm at Battleford. Only the single bird noted.

With the exception of the pipit and the sandpiper, and possibly the Burrowing Owl, all of which appear to be showing a definite northward trend, the other observations appear to represent erratic shifts, perhaps related to drought conditions. No Lark Buntings have been seen anywhere in the area except in 1935.

But to return to the woodchucks. I cannot do better than to list these observations from year to year as follows:

1932: H. Coons showed me the skin of an animal he had trapped that spring south of Robin Hood, which he thought was a young Badger, but was that of a Woodchuck. The same spring I observed a Woodchuck on the roadside near Medstead, and saw a few skins in Hallas and Sons' store there, which had been brought in by the Birch Lake Indians.

1933: In passing an Indian camp near Manito Lake near Neilburg, I saw three skins drying by the tent. The skins were not yet dry and were probably taken locally, although the Indian, Jim Gopher, had been at Onion Lake a week or so before.

1934: While passing through Paynton in July I saw several men looking at a dead animal on the sidewalk. It had been shot by $C$. Dobie in his farmyard five miles north of Paynton. None of the men had recognized it as a Woodchuck until I told them.

1935: Several Indians from Moosomin reservation near Meota told me that they had seen and trapped these animals that year. I was shown two skins.

1936: I ran over a Woodchuck on the road near Hillside post office, three miles south and four miles west of Sandwith. There were several other reports between Turtleford and North Battleford.
1937: Old Wapanase, a Saulteaux Indian living at Jackfish Lake, trapped, skinned and ate a Woodchuck, and thought the matter of sufficient interest to tell me. T. Lecky, a farmer at Iffley, found a den with young on his farm and took photographs. I saw these personally. In August while patrolling on Highway 4, 13 miles south of Battleford, stopped the car to observe a Woodchuck on the roadside. I was able to approach within a few yards before it went into its burrow. Throughout the year, various people have told me of an animal like a Badger, only smaller, near their farm buildings.

In support of the theory that these animals really are quite new to these farming districts, let me add that it was quite unfamiliar to $\mathrm{Mr}$. Dobie and $\mathrm{Mr}$. Lecky. Both had been farming here for upward of 30 years, and both are well educated men interested in wildlife.

Possibly the virtual disappearance of the Badger in these parts since 1931 may have had something to do with it. It may be that the Woodchucks are now venturing to leave their northern home moving south into more open country with comparative safety. Some Woodchucks are evidently stopping tc breed.

NOTE: The above account has been abridged from a report from Robert D Symons, then a Field Officer with the Saskatchewan Department of Natura Resources at Meota, Saskatchewan, to Fred A. Dunk, Director of the Provincia Museum, Regina. It was dated September 1937.

Dr. Fred G. Bard kindly asked Fred $W$. Lahrman to loan this item to $m$ because of its possible historical in terest, along with a collection of letter from Laurence B. Potter and a list of bir specimens collected by Charles $F$ Holmes. I felt the account of th Woodchuck was well worth sharing. C. Stuart Houston, 863 University Drive Saskatoon, Saskatchewan. S7N 0J8 